\title{
Design of Hybrid Fractal Boundary Antenna for RF Energy Harvesting Applications
}

\author{
Amritpal Kaur, Balwinder S. Dhaliwal, Suman Pattnaik
}

\begin{abstract}
The fractal antennas have multiband behavior and also have the capabilities of the size reduction as compared to the other patch antennas. Ahybrid fractal boundary antenna has been designed and simulated in this paper for radio frequency energy harvesting (RFEH). The designed antenna has the multiband behavior, as it resonates at the two frequencies. The multiband behavior of the antenna helps in harvesting the energy from various frequencies band and improves the output of the circuit. This hybrid fractal boundary antenna uses the microstrip feed line to improve the matching performance of the antenna.

Index Terms: Fractal antenna, Hybrid fractal boundary antenna, Radio Frequency (RF), Energy Harvesting (EH).
\end{abstract}

\section{INTRODUCTION}

The emergent need of wireless devices requires power wirelessly hence motivating research towards the energy harvesting and it is the requirement of now days. The RF energy harvesting (RFEH) is a way out toward this. RFEH gather the radio frequency (RF) energy existing in the environment and transform it into the required electrical energy [1]. RFEH technique has the ability to produce low amount of power mostly required for large number of devices now days. RF energy is abundantly present in the environment from the mobile communication systems, radio broadcasting, wireless local area network (WLAN) and in many other forms of systems that uses the RF signals for communication. The RFEH system needs a harvesting system to scavenge the RF energy from the environment. The RFEH system includes the antenna, matching circuit, rectifier and energy storage device to store the energy. This system is also referred to as rectenna [2].

Revised Manuscript Received on June 22, 2019.

Amritpal Kaur, Department of Electronics and Communication Engineering, Guru Nanak Dev Engineering College, Ludhiana, India. E-mail: amritk1410@ gmail.com

Balwinder Singh Dhaliwal, Department of Electronics and Communication Engineering, Guru Nanak Dev Engineering College, Ludhiana, India. E-mail: bsdhaliwal@ymail.com

Suman Pattnaik, Department of Electronics and Communication Engineering, SSIET, Dera Bassi, India. E-mail: sumanbhagat1199@gmail.com
The RF energy sources divided in two parts ambient and the dedicated energy sources. Ambient sources harvests the energy from the RF energy present in the environment and are not dedicated but the dedicated rectennas harvests energy only from their dedicated source [3]. In paper [4]authorsdescribed,the various sources of RFEH shown with their frequency band and the amount of power that can harvested from them.The main part of the RFEH system is antenna, which captures the RF energy and converts it into the usable form. In paper[5] antenna designed for RFEH operates in the $2.45 \mathrm{GHz}$ band with high efficiency.

Fractal antenna gainedboundary antenna analyzed in [8] is a triple band circularly polarized antenna and suited for wireless applications. In [9] the UWB antenna designed with the fractal popularity due its multiband feature and size reduction capabilities. The fractal antennas designed for RFEH in [6], [7] gives the multiband frequency operation. The Koch fractal boundary exhibited the omnidirectional patterns over wide range with the compact size of antenna. A hybrid fractal boundary antenna has been designed in [10] with Koch and Minkowski curve combination on the patch boundary. This antenna resonates in triple bands with high radiation efficiency.

In this paper, a hybrid fractal boundary antenna is proposed for RFEH. The Section I in paper presents the introduction and Section II describes the proposed antenna design Section III is about the results and discussions and the last Section IV is concludes the paper.

\section{PROPOSED ANTENNA DESIGN}

The starting shape of the antenna is square patch and then the circular slot is cut with the radius equal to half of the length of basic square and the crown square patch added to the geometry forms a crown fractal antenna. This geometry is proposed and analyzed in [6]. The authors in [6] have shown that as the antenna iterations increases the antenna behaves as multiband and the frequency separation decreases. The crown square fractal antenna in [6] has been modified and proposed as the hybrid fractal boundary antenna. The Fig. 1(a) shows the crown square fractal antenna after adding the Minkowski curve at the boundaries of this antenna shown in Fig. 1(b) and Fig. 


\section{Design of Hybrid Fractal Boundary Antenna for RF Energy Harvesting Applications}

1(c) shows the proposed hybrid fractal boundary antenna.

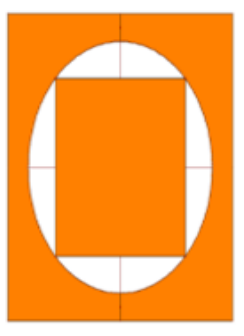

a

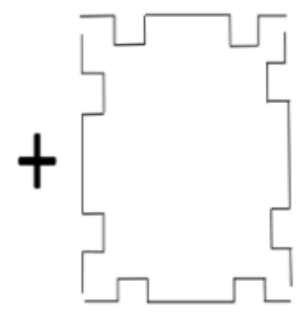

b

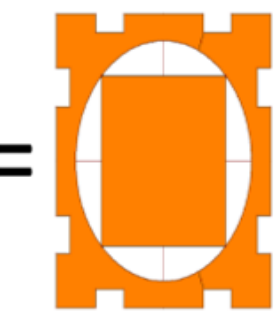

c
Fig. 1 (a) Crown square fractal antenna, (b) Minkowski curve, (c) Hybrid fractal boundary antenna

The antenna patch designed with thickness of $4 \mathrm{~mm}$ and dielectric constant used is 3.5. The outer or base square of the hybrid fractal antenna dimension 46.5 $\mathrm{mm} \times 46.5 \mathrm{~mm}$ and radius of the circle is $19 \mathrm{~mm}$ with the inner square of $26.9 \mathrm{~mm} \times 26.9 \mathrm{~mm}$ has the slot of crown square fractal antenna. The Minkowski curve added to the boundary of the antennahas the length and depth of $6 \mathrm{~mm}$ and $2 \mathrm{~mm}$ respectively and forming a hybrid fractal boundary antenna.

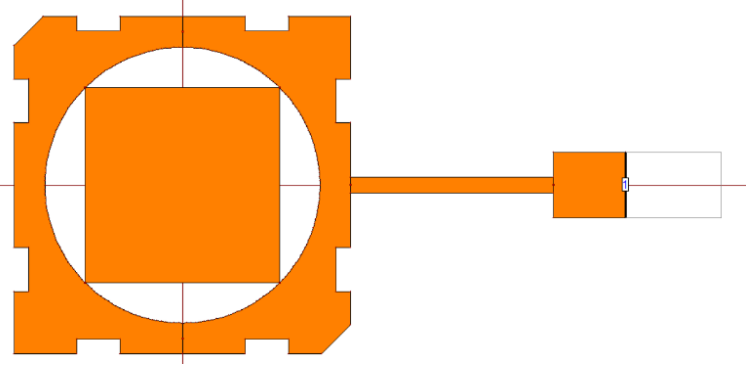

Fig. 2 Hybrid Fractal Boundary Antenna with Microstrip Feedline

This antenna geometry has been tapered at the opposite sideswith dimensions of $4 \mathrm{~mm} \times 4 \mathrm{~mm}$.Fig. 2 shows the modified hybrid fractal boundary antenna with the Minkowski curve and tapering on the opposite sides to enhance the results with the microstrip feed line. This fractal antenna employed the microstrip feed line to improve the matching properties. Themicrostrip feed line is of two sections and the dimensions are $\mathrm{L} 1=28 \mathrm{~mm}$ and $\mathrm{W} 1=2.2$ $\mathrm{mm}$ the second section is of $\mathrm{L} 2=10 \mathrm{~mm}$ and $\mathrm{W} 2=9$ $\mathrm{mm}$ as in [6]. Table 1 shows the dimensions for this hybrid fractal boundary antenna.

Table 1 Hybrid fractal boundary antenna dimensions

\begin{tabular}{|c|c|}
\hline Parameter & Value \\
\hline Length & $46.5 \mathrm{~mm}$ \\
\hline Width & $46.5 \mathrm{~mm}$ \\
\hline Circle Radius & $19 \mathrm{~mm}$ \\
\hline Feed Length & $28 \mathrm{~mm}$ \\
\hline
\end{tabular}

\begin{tabular}{|c|c|}
\hline Feed Width & $10 \mathrm{~mm}$ \\
\hline Feed Length & $2.2 \mathrm{~mm}$ \\
\hline Feed Width & $9 \mathrm{~mm}$ \\
\hline
\end{tabular}

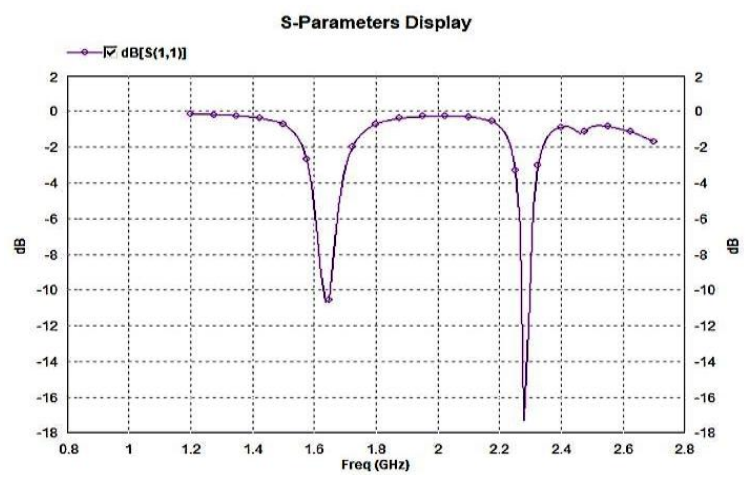

Fig. $3 \mathrm{~S}_{11}$ plot of the fractal antenna

\section{RESULTS AND DISCUSSION}

The simulation results of the designed antenna have been discussed in this section. The antenna designed and simulated in the IE3D software, which is a high performance EM wave simulator.Fig. 3 shows the $S_{11}$ plot of the fractal antenna with two resonant frequencies. The first resonant frequency is $1.63 \mathrm{GHz}$ with the return loss of $-10.67 \mathrm{~dB}$ and the second resonant frequency is $2.27 \mathrm{GHz}$ with return loss of $17.08 \mathrm{~dB}$. The proposed antenna has dual band behavior and its fundamental frequency has better matching than that of the reference antenna of [6]. So the proposed antenna has improved results as compared to earlier existing design. The bandwidth at the first resonating frequency of $1.63 \mathrm{GHz}$ is $20 \mathrm{MHz}$ and at the second resonating frequency, of $2.27 \mathrm{GHz}$ is $30 \mathrm{MHz}$.

The crown square fractal antenna in [6] resonates at frequencies $1.575 \mathrm{GHZ}$ and $2.6 \mathrm{GHz}$ with the return loss of $-9.3 \mathrm{~dB}$ and $-16.8 \mathrm{~dB}$ respectively so the reference antenna do not have significant bandwidth at fundamental frequency.

So we got the antenna resonating at both the frequencies, with improved impedance matching as seen in terms of the return loss and also it has decreased the frequency separation. This antenna helps in harvesting the RF energy at two resonant frequencies. 


\section{CONCLUSION}

The hybrid fractal boundary antenna proposed for RFEH, resonates at the two frequencies, which are $1.63 \mathrm{GHz}$ and $2.27 \mathrm{GHz}$ with the return loss of -10.67 $\mathrm{dB}$ and $-17.08 \mathrm{~dB}$ respectively. The antenna has bandwidth of $20 \mathrm{MHz}$ and $30 \mathrm{MHz}$ at the first and second resonating frequency. The proposed hybrid fractal boundary antenna shows the improvement in the results from the previous reference antenna in the case of its return loss and frequency separation. The further possibility of improvements in results is there to make the antenna more efficient.The hybrid fractal boundary antenna has great potential for RF energy harvesting due to its advantages of multiband and simple design.

\section{REFERENCES}

[1] D. Y. Choi, S. Shrestha, J. J. Park, and S. K. Noh, "Design and performance of an efficient rectenna incorporating a fractal structure," Int. J. Commun. Syst., no. 4, 2014, pp. 661679.

[2] M. Mrnka, P. Vasina, M. Kufa, V. Hebelka, and Z. Raida, "The RF Energy Harvesting Antennas Operating in Commercially Deployed Frequency Bands: A Comparative Study," Int. J. Antennas Propag., vol. 2016, pp. 1-11.

[3] D. Mishra, S. De, S. Jana, S. Basagni, K. Chowdhury, and W. Heinzelman, "Smart RF energy harvesting communications: Challenges and opportunities," IEEE Commun. Mag., vol. 53, no. 4, 2015, pp. 70-78.

[4] J. Jose, S. George, L. Bosco, J. Bhandari, F. Fernandes, and A. Kotrashetti, "A Review of RF Energy Harvesting Systems in India," in 2015 International Conference on Technologies for Sustainable Development (ICTSD), 2015, pp. 1-4.

[5] Q. Awais, Y. Jin, H. T. Chattha, M. Jamil, H. Qiang, and B. A. Khawaja, "A Compact Rectenna System With High Conversion Efficiency for Wireless Energy Harvesting," IEEE Access, vol. 6, 2018, pp. 35857-35866.

[6] Y. Wang and S. Liu, "A New Modified Crown Square Fractal Antenna," 2008 Int. Conf. Microw. Millim. Wave Technol. Proceedings (ICMMT), vol. 1, 2008, pp. 400-402.

[7] Y. Shi, Y. Fan, J. Jing, L. Yang, Y. Li, and M. Wang, "An efficient fractal rectenna for RF energy harvest at $2.45 \mathrm{GHz}$ ISM band," Int. J. RF Microw. Comput. Eng. , 2018, pp. 1-8.

[8] V. V Reddy and N. V. S. N. Sarma, "Triband Circularly Polarized Koch Fractal Boundary Microstrip Antenna," IEEE Antennas Wirel. Propag. Lett., vol. 13, 2014, pp. 1057-1060.

[9] D. Li, F. Zhang, Z. Zhao, L. Ma, and X. Li, "UWB Antenna Design Using Patch Antenna with Koch Fractal Boundary," in 2012 International Conference on Microwave and Millimeter Wave Technology (ICMMT), 2012, vol. 3, pp. 1-3.

[10] N. Sharma, S. Kaur, and B. S. Dhaliwal, "A New Triple Band Hybrid Fractal Boundary Antenna," in 2016 IEEE International Conference on Recent Trends in Electronics, Information \& Communication Technology (RTEICCT), 2016, pp. 874-878

\section{AUTHOR'S PROFILE}

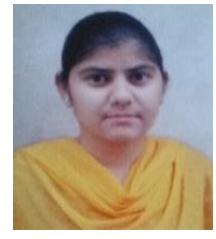

Amritpal Kauris currently pursuing the M. Tech in the field of Electronics and Communication Engineering from Guru Nanak Dev Engineering College, Ludhiana, India. She has received the B. Tech degree in Electronics and Communication Engineering from Guru Nanak Dev Engineering College in 2017. Her main research interest is Antenna

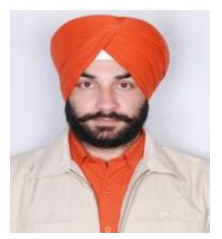

Balwinder Singh Dhaliwaliscurrently working as Assistant Professor at Guru Nanak Dev Engineering College, Ludhiana in Electronics and Communication Engineering Department. In 2016, he has received the Ph.D. degree in the field of fractal antenna design from IKG Punjab

Technical University, Jalandhar, India. He has received his $M$. Tech degree in Electronics and Communication Engineering in 2006 and B. E. degree in 2000 in the Electronics and Communication Engineering from the Guru Nanak Dev Engineering College, Ludhiana, India. He has been listed in the Who's Who of the world and he is member of IEEE, ISTE, IE (I). His research areas are fractal antenna design using artificial neural networks and Bioinspired computing based algorithms

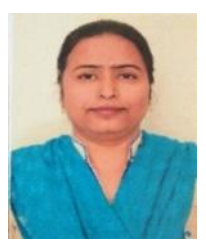

Suman Pattnaikis presently working as an Associate Professor in Electronics and Communication Engineering Department at PTU College in Dera Bassi Punjab. She has received her Ph.D. degree from IKG Punjab Technical in Electronics and Communication Engineering. She has completed her M. E. in Electronics and Communication Engineering from Punjab University in 2011 and AMIE from Institution of Engineers in 1996. She has published research paper in National and International Journals and Conferences won the best paper awards. She has served as the Senior Group Engineer in Punjab Communications Limited and has eleven years of industrial exposure. Her main research interests are neural networks, biomedical engineering and soft computing techniques.

Design. 